\title{
Design of Biodegradable Quadruple-shaped DRA for WLAN/Wi-Max applications
}

\author{
Pramod Kumar, Santanu Dwari, \\ Department of Electronics Engineering, Indian Institute of Technology (Indian School of Mines), Dhanbad, \\ Jharkhand, India \\ er.pramodkumar@gmail.com; santanu_dwari@rediffmail.com \\ Utkarsh \\ Department of Electronics and Communication, Inderprastha Engineering College, Ghaziabad, U.P., India \\ utk2994@gmail.com \\ Jitendra Kumar \\ Microwave Plasma Group, Institute for Plasma Research, Gandhinagar, Bhat, Gujarat, India \\ jitu.kumar87@gmail.com
}

\begin{abstract}
A novel Quadruple-shaped Dielectric Resonator Antenna (DRA) excited by a coaxial feed is investigated. The dielectric used for investigation is biodegradable polymer based dielectric material having a dielectric constant $\left(\varepsilon_{r}\right)$ of 3.45 and dielectric loss tangent $(\delta)=0.02$. The resulting antenna offers broad impedance bandwidth of $63.2 \%$ for $\left|S_{11}\right|<-10 \mathrm{~dB}$ from 2.8 to $5.2 \mathrm{GHz}$ frequency band. This antenna is suitable for practical use in WLAN $(5.15-5.35 \mathrm{GHz})$ and Wi-Max (3.4-3.69 GHz) applications. The results show the peak gain of the antenna is $4.5 \mathrm{dBi}$ at resonant frequency $3.8 \mathrm{GHz}$. It is also observed that the new proposed structure of Quadrupleshaped DRA offers broadside radiation patterns and high efficiency for the entire operating band. The simulated and experimental results are well in agreement.
\end{abstract}

Index Terms - Biodegradable Polymer, Dielectric Resonator Antenna, Quadruple-shaped DRA, Wi-Max, WLAN

\section{INTRODUCTION}

To enrich with new services to more users higher bit rate is indispensable that's why wireless systems is shifting towards the microwave frequency bands with low interference and more available bandwidth. However, at these frequencies, conductor loss is significant, which affects the gain and efficiency of fabricated metallic antennas. For better utilization of microwave frequencies regarding wireless applications, antennas with simple fabrication, higher efficiency, and larger impedance bandwidth is statutory.

Dielectric Resonator Antennas (DRAs) have abundant captivating features such as wider impedance bandwidth with higher radiation efficiency due to the deprivation of surface wave and conductor 
losses [1]. Challenging part is a fabrication of DRAs as they are made of high permittivity ceramics, which are naturally hard and extremely difficult to cut. The fabrication of these three dimensional (3D) structures are onerous at microwave frequencies where the size of the antenna is reduced to the millimeter or sub-millimeter range.

In recent years the most standard dielectric resonators (DRs) configurations such as rectangular, hemispherical, cylindrical etc., have been modified in the pursuit of enhanced operational bandwidths [2-7]. As compared to cylindrical or hemispherical DRA, Rectangular Dielectric Resonator Antenna (RDRA) provides more degrees of freedom which can be used to control the impedance bandwidth of the antenna [3].

Significant efforts with different techniques are adopted on DRAs such as Stacked DRs [8], Multisegment DRs [9], as well as more tortuous structures as see in [10-11] led to enhanced band widths of about 35\%-40\%. In [12] stacked and embedded DRs also claimed the possibility to achieve prodigious operational bandwidths up to more than $60 \%$, but make the manufacturing process of antenna complicated and expensive. The use of multiple resonating modes was adopted in [13]. More recently a new class of DRA known as Super-shaped DRA [14] is introduced. These antennas render freedom for the design of the DRs. Quadruple-shaped DRAs overt the good flexibility for matching bandwidth and radiation patterns while preserving broadside radiation and ease of manufacturing.

In this paper a novel rectangular DRA based on Quadruple-shaped profile excited by a coaxial feed is developed and investigated for WLAN/Wi-Max applications. The basic idea of proposed DRA is to affiliate the use of biodegradable polymer based dielectric material which is easily available and machinable materials. Biodegradable PLA for DRA material is special polymers which are made from renewable resources instead of non-renewable petroleum based resources. This makes it relatively cost efficient to produce. Biodegradable means it naturally degrades when exposed to the environment after the use while during the use it will not decompose. It will help in managing the electronic waste (e-waste) as it is becoming a huge concern. This choice helps us with inexpensive DRAs with experimentally verified performance regarding broad impedance bandwidth, radiation stability and radiation efficiency. It is found that the linear polarized proposed antenna offers $63.2 \%$ impedance bandwidth for $\left|\mathrm{S}_{11}\right|<-10 \mathrm{~dB}$ from 2.8 to $5.2 \mathrm{GHz}$. To authenticate the simulation, measurement was carried out, and reasonable results are achieved.

\section{ANTENNA DESIGN AND CONFIGURATION}

Design guide flowchart of proposed antenna is shown in Fig.1. The different views of the proposed antenna are shown in Fig. 2, which is a simple a type of rectangular DRA. The designing of antenna is done by using ANSYS HFSS [15] and validated with CST Microwave Studio [16] as well as experimental measurements.

The dimensions of DRA along $x$-, and $y$-, directions are equal (length $=$ width $=18 \mathrm{~mm}$ ) and along $z$ direction is height $H(H=29 \mathrm{~mm})$. The antenna is fed from the bottom side via the coaxial feed at the 


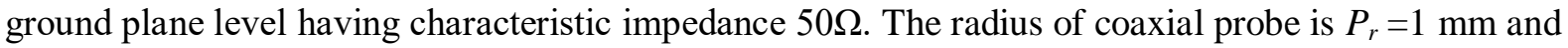
height $P_{H}=14 \mathrm{~mm}$, as shown in Fig. 3 for RDRA. The strip size (length of one constituent) of the Quadruple is taken as $7.4 \mathrm{~mm}$.

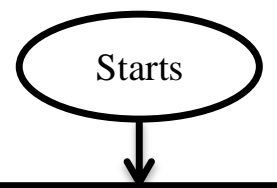

Identify the operating frequency and band

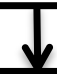

Calculate the required parameter of RDRA

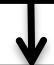

Design and simulate the RDRA using EMsolver as reference antenna
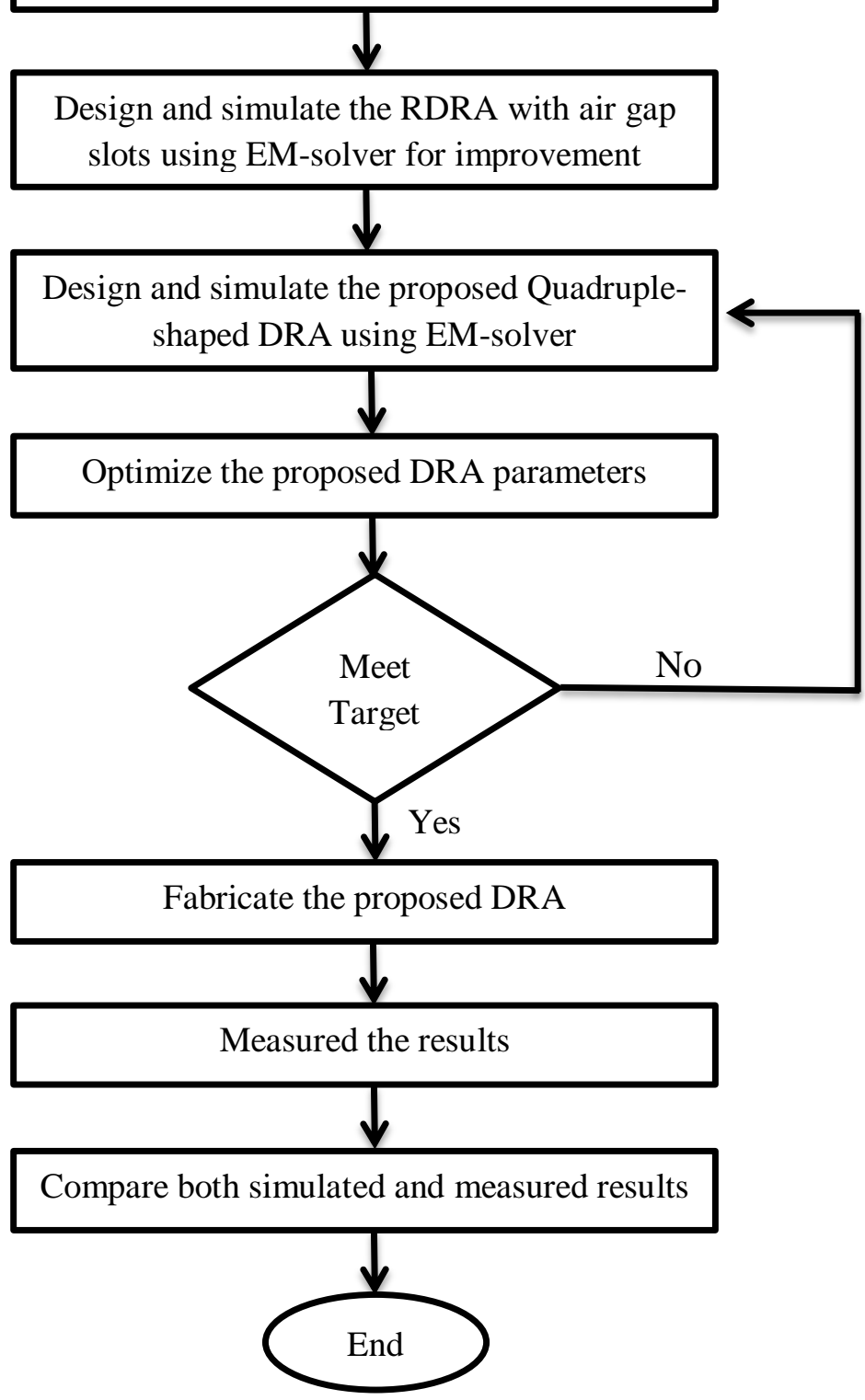

Fig. 1 Design guide flowchart of proposed Quadruple-shaped DRA 


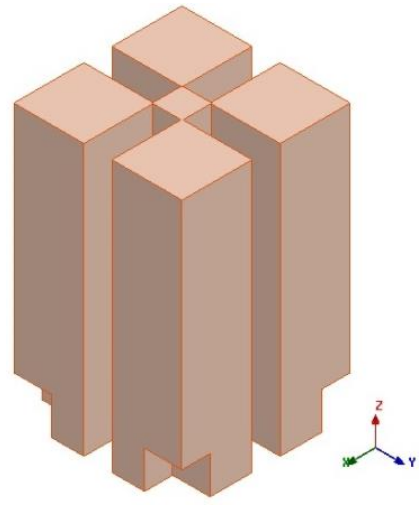

(a)

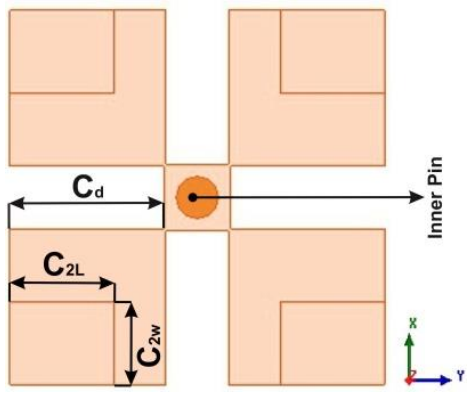

(b)

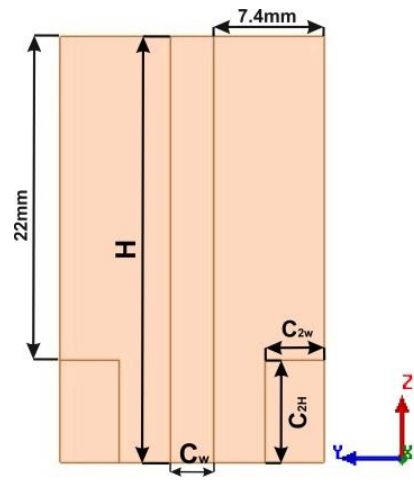

(c)

Fig. 2 Proposed DRA geometry: (a) Isometric view, (b) Top view, (c) Side View

The theoretical formula for resonant frequency $\left(f_{r}\right)$ of a RDRA is given as [1]:

$$
f_{r}=\frac{c}{2 \pi \sqrt{\varepsilon_{r}}} \sqrt{k_{x}^{2}+k_{y}^{2}+k_{z}^{2}}
$$

where " $\varepsilon_{r}$ " is the dielectric constant of the RDRA, " $c$ " is the speed of light in free space and symbol " $k_{x}$ ", " $k_{y}$ " and " $k_{z}$ " represents the wave numbers in the $x, y$ and $z$ directions respectively. The dielectric used for examination of DRA is polymer based ceramic material having a dielectric constant $\left(\varepsilon_{\boldsymbol{r}}\right)$ of 3.45 and dielectric loss tangent $(\boldsymbol{\delta})=0.02$. RDRA is braced by a square ground plane as shown in Fig. 3. The ground plane of thickness $G_{T}=1 \mathrm{~mm}$ and sides $\boldsymbol{G}_{S}=100 \mathrm{~mm}$ is made up by copper.

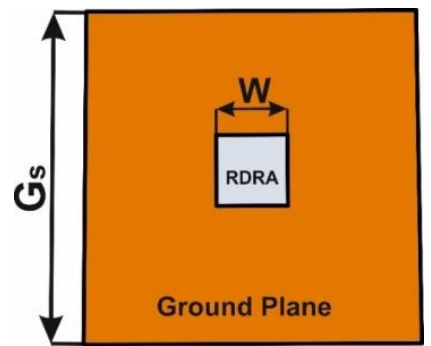

(a)

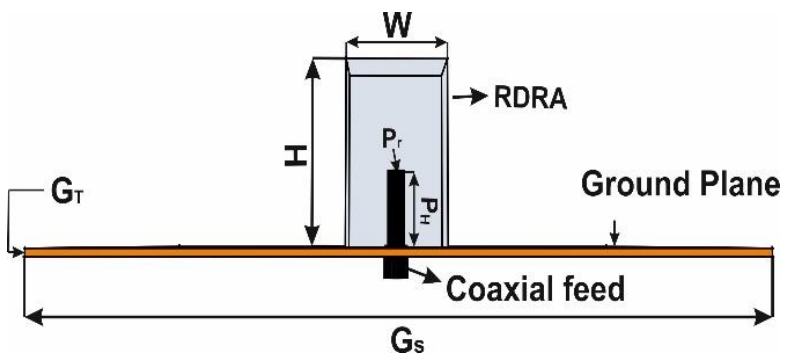

(b)

Fig. 3 Rectangular DRA as Reference Antenna: (a) Top View, (c) Side View

The development procedure of the Quadruple-shaped DRA includes three steps: First, a rectangular shaped DR as (reference antenna) shown in Fig. 4(a) is taken and second, air gap slots [ $\left.C_{w}=3.2 \mathrm{~mm}\right)$ $\left.\mathrm{x}\left(C_{d}=7.2 \mathrm{~mm}\right) \mathrm{x}(H=29 \mathrm{~mm})\right]$ are inserted in it to reduce Q-factor as shown in Fig. 4(b). This DRA is named as a modified antenna with side cut. Then to further modify the shape, cutting height $\left(C_{2 H}\right)$, cutting length $\left(C_{2 L}\right)$, and cutting width $\left(C_{2 W}\right)$ is done to achieve Quadruple-shaped DRA as shown in Fig. 4(c).

The permittivity of the proposed antenna is altered with the perforated slots cut in the DRA and it will become effective permittivity $\left(\varepsilon_{e f f}\right)$ of the DR with a smaller value. Thus, as the $\varepsilon_{\text {eff }}$ decreases, the Q factor decreases and hence the bandwidth is improved significantly. Hence, $\varepsilon_{e f f}$ of proposed DRA can be calculated by modifying the dielectric waveguide model (DWM) equation as [17]: 


$$
\varepsilon_{\text {eff }}=\frac{\varepsilon_{r} V+\varepsilon_{0} V_{\text {slots }}}{V+V_{\text {slots }}}
$$

where $V$ and $V_{\text {slots }}$ are the volume of proposed DRA and air gap slots of DRA respectively.

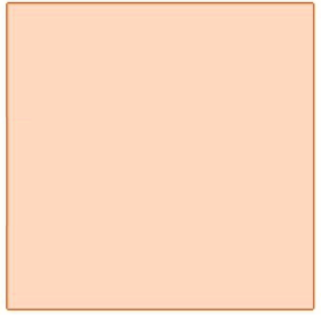

(a)

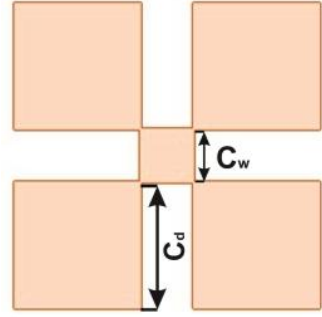

(b)

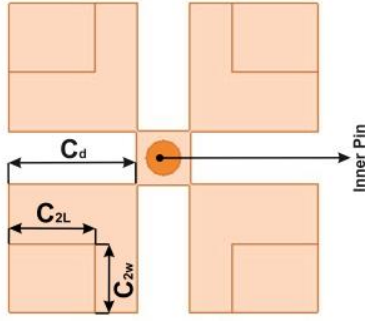

(c)

Fig. 4 Evolutionary steps of Quadruple-shaped DRA: (a) Reference antenna, (b) Modified antenna with side cut, (c) Proposed antenna

The main aim of research is to enhance the impedance bandwidth of DRA with effective cost which can use for WLAN/Mi-Max applications. Carving out side's portion also shifted the operating band in high frequency as well as improved the reflection coefficient. The comparison of reflection coefficient versus frequency for Quadruple-shaped, RDRA and modified antenna with side cuts is shown in Fig. 5. The simulated results show that proposed antenna (Quadruple-shape DRA) is having a sharp resonance dip of $S_{11}$ is $-41 \mathrm{~dB}$ at $3.8 \mathrm{GHz}$ with $63.2 \%$ impedance bandwidth for $\left|S_{11}\right|<-10 \mathrm{~dB}$ which is highest as compared to RDRA and side cut DRA. The RDRA is having a resonant dip of $S_{11}$ is $-18 \mathrm{~dB}$ only at $2.7 \mathrm{GHz}$ with $53.3 \%$ fractional bandwidth for $\left|S_{11}\right|<-10 \mathrm{~dB}$, whereas the resonant dip of $S_{11}$ for modified side cut DRA is $-24 \mathrm{~dB}$ at $3.8 \mathrm{GHz}$.

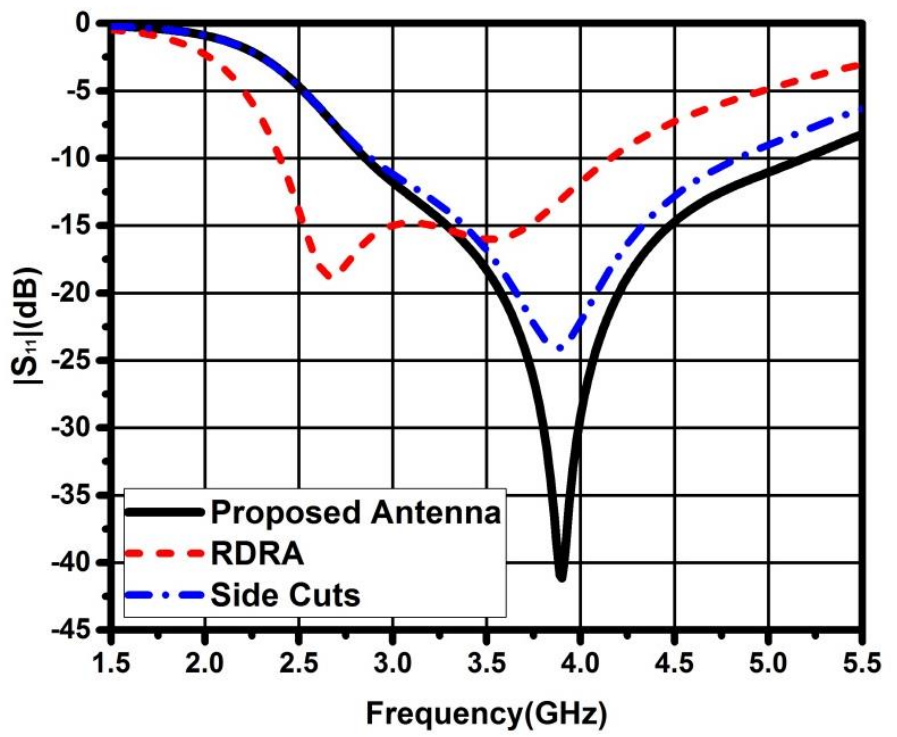

Fig. 5 Reflection coefficient versus frequency for reference antenna (RDRA), modified antenna with side cuts and proposed antenna (Quadruple-shaped)

A parametric study is carried out to characterize the proposed DRA and the influence of various parameters on the response of DRA. The simulated result of reflection coefficient versus frequency 
for different cutting depth $\left(C_{d}\right)$ is shown in Fig. 6. It is noticed that if cutting depth $\left(C_{d}\right)$ is $7.2 \mathrm{~mm}$ and cutting width $\left(C_{w}\right)$ is $3.2 \mathrm{~mm}$ then antenna successfully enhances the bandwidth by $300 \mathrm{MHz}$ with respect to a reference antenna due to efficient impedance matching.

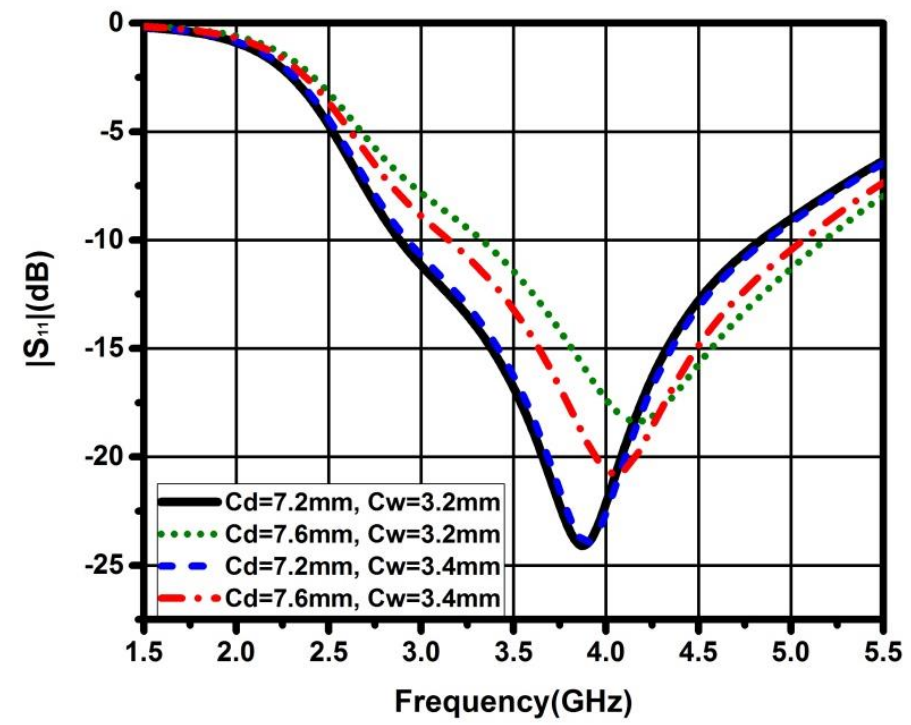

Fig. 6 Variation of reflection coefficient versus frequency curve for different value of cutting depth

In effort of further improvement of the result, the bottom edges of DR from all four sides are engraved out, which successfully enhanced the bandwidth from $52.6 \%$ to $63.2 \%$. To confirm this parametric analysis, simulated reflection coefficient plot of the DRA versus frequency for different value of cutting bottom edges is shown in Fig. 7. This analysis shows that cutting bottom edge not only affects the impedance matching at the resonant frequency, but it also affects the impedance bandwidth of the antenna. It is observed that the optimum impedance bandwidth is achieved by choosing values for $C_{2 H}=8 \mathrm{~mm}, C_{2 L}=5 \mathrm{~mm}$ and $C_{2 W}=4 \mathrm{~mm}$. Table I shows the comparison of the proposed DRA with reference RDRA and side cuts DRA.

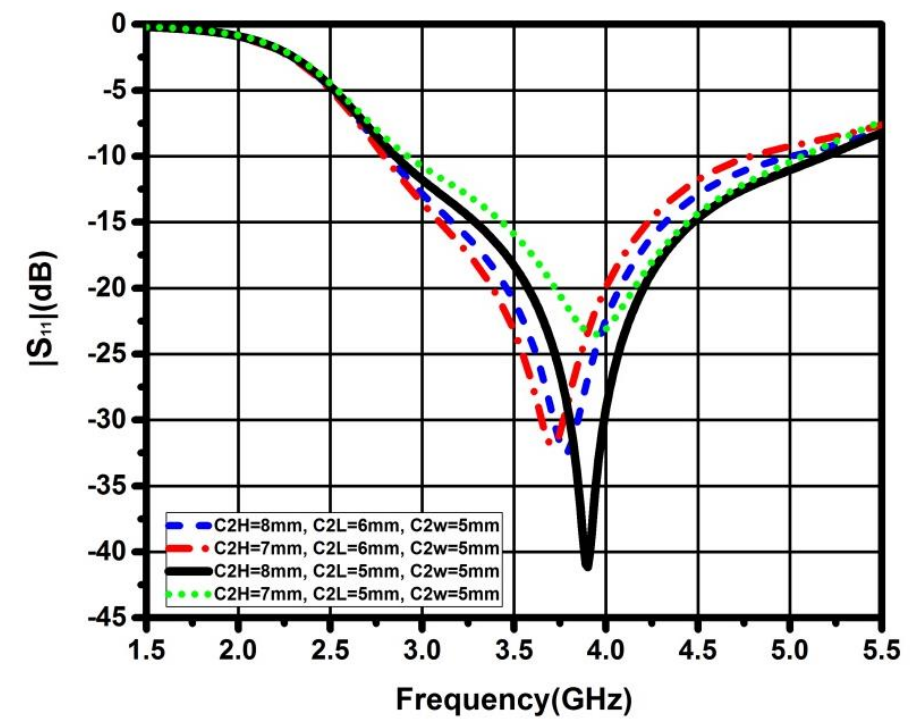

Fig. 7 Variation of reflection coefficient versus frequency curve for different value of cutting bottom edges 
Journal of Microwaves, Optoelectronics and Electromagnetic Applications, Vol.16, No. 3, September 2017873 DOI: http://dx.doi.org/10.1590/2179-10742017v16i31019

TABLE I: COMPARISON TABLE OF SIMULATED RESULTS OF DIFFERENT STRUCTURE

\begin{tabular}{ccccc}
\hline Parameters & $\mathbf{f}_{\mathbf{r}}(\mathbf{G H z})$ & $\mathbf{B W}(\mathbf{G H z})$ & $\mathbf{B W}(\boldsymbol{\%})$ & Gain $(\mathbf{d B})$ \\
\hline RDRA & 2.7 & 1.8 & 53.3 & 4.6 \\
Side Cuts & 3.8 & 2 & 52.6 & 4.3 \\
Proposed DRA & 3.8 & 2.4 & 63.2 & 4.5 \\
\hline \multicolumn{4}{r}{$B W-$ Bandwidth,$f-$ Resonant frequency }
\end{tabular}

Fig. 8 shows the 3D gain pattern of proposed antenna at its resonant frequency $3.8 \mathrm{GHz}$. The peak gain $4.5 \mathrm{~dB}$ is dignified at resonant frequency with broad side pattern. Fig. 9 shows the electric field distribution in proposed DRA at its resonant frequency $3.8 \mathrm{GHz}$. The field distribution clearly verifies the presence of Quasi-TM $\mathrm{TM}_{111}$ like mode in reference to the corresponding cylindrical resonator mode [18].

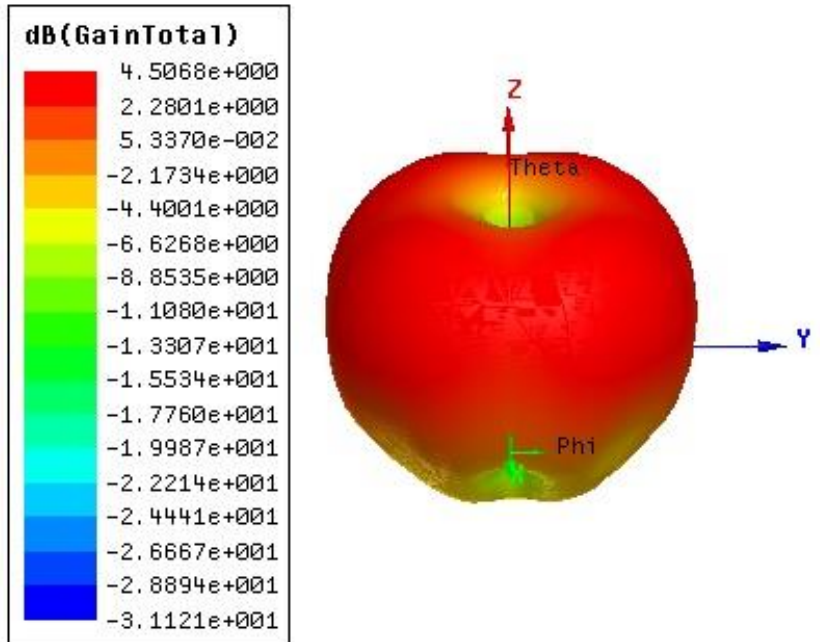

Fig. 8 3D gain pattern of proposed antenna at $3.8 \mathrm{GHz}$

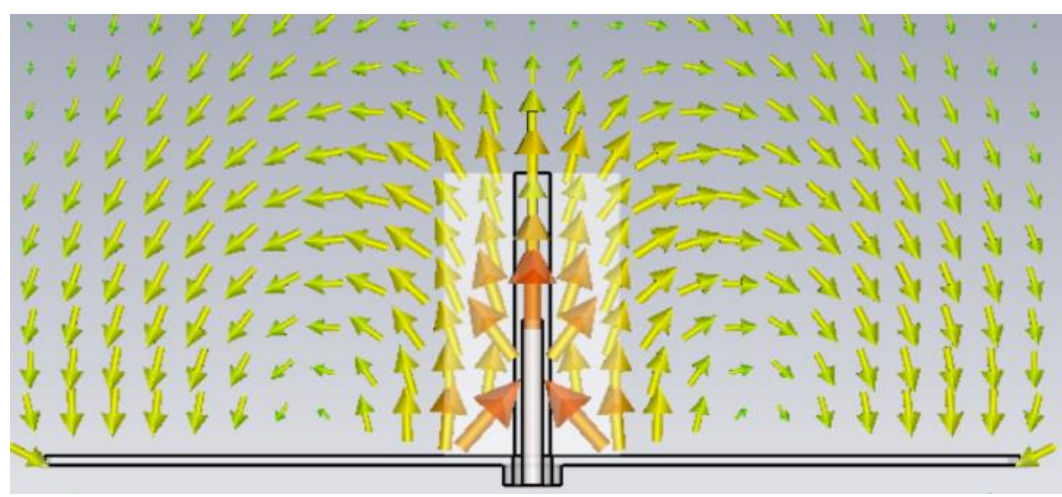

Fig. 9 Electric field distribution at $3.8 \mathrm{GHz}$

The comparison plot of radiation efficiency versus the frequency is shown in Fig. 10. The efficiency of the DRA is more than $80 \%$ for complete band of operation i.e. 2.8 to $5.2 \mathrm{GHz}$. Radiated efficiencies of the proposed antenna are in very good agreement with each other. Table II shows the value and expansion of used abbreviations. 


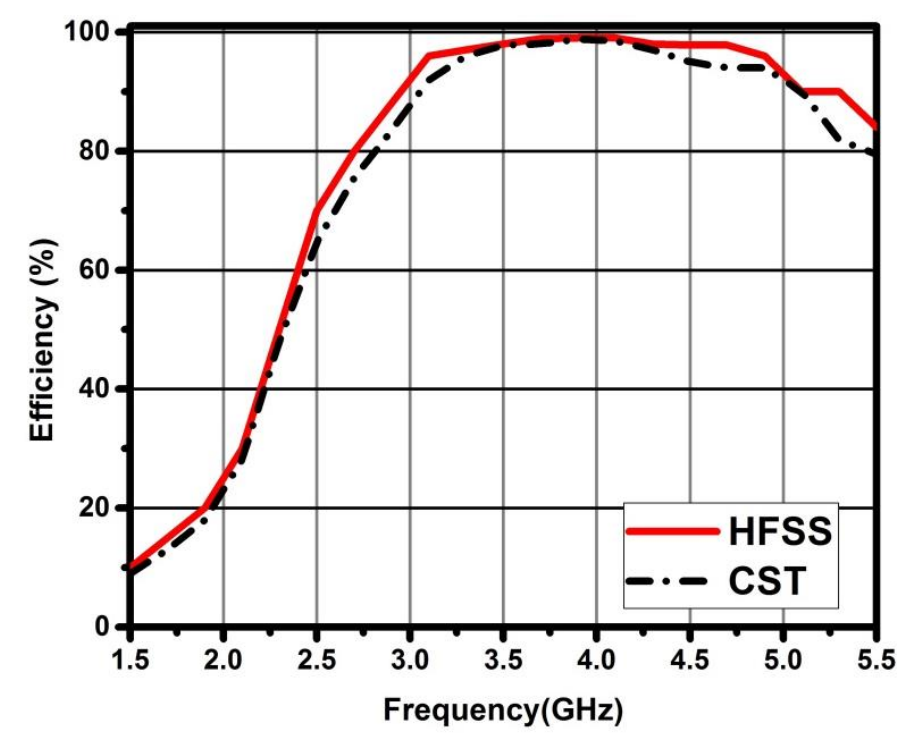

Fig. 10 Comparison of antenna efficiency as a function of frequency for Quadruple-shaped DRA

TABLE II: VALUE AND EXPANSION OF ABBREVIATIONS

\begin{tabular}{ccc}
\hline Abbreviation & Expansion & Dimension (mm) \\
\hline $\mathrm{W}$ & DRA Width & 18 \\
$\mathrm{H}$ & DRA Height & 29 \\
$\mathrm{G}_{\mathrm{s}}$ & Ground Plane Side & 100 \\
$\mathrm{G}_{\mathrm{T}}$ & Ground Plane Thickness & 1 \\
$\mathrm{P}_{\mathrm{r}}$ & Pin Radius & 1 \\
$\mathrm{P}_{\mathrm{H}}$ & Pin Height & 14 \\
$\mathrm{C}_{\mathrm{w}}$ & Side Cut Width & 3.2 \\
$\mathrm{C}_{\mathrm{d}}$ & Side Cut Depth & 7.2 \\
$\mathrm{C}_{2 \mathrm{~L}}$ & Bottom Cut Length & 5 \\
$\mathrm{C}_{2 \mathrm{H}}$ & Bottom Cut Height & 8 \\
$\mathrm{C}_{2 \mathrm{~W}}$ & Bottom Cut Width & 4 \\
\hline
\end{tabular}

\section{COMPARATIVE STUDY}

The comparative study is done to highlight the advantages of biodegradable polymer based DRA over alumina (ceramic) based conventional DRA. The dimensions of both antenna i.e. polymer based DRA and alumina based conventional DRA are considered same for comparison except the height. The height and feed of the alumina based DRA is optimized to matche the resonance frequency. Here, heigt $=25.3 \mathrm{~mm}$ taken for alumina based DRA while $29 \mathrm{~mm}$ used for proposed DRA. Fig. 11 shows the comparative plots of reflection coefficient versus frequency and the variation of peak gain versus frequency is shown in Fig. 12. It is observed that polymer based DRA achieves wider bandwidth compare to alumina based DRA. It is also noticed that the peak gain over the operating band is remain same. Except these entire advantage polymer based DRA have also many more benefits such as low cost, easy fabrication, light weight and higher thermal conductivity as tabulated in Table III. 


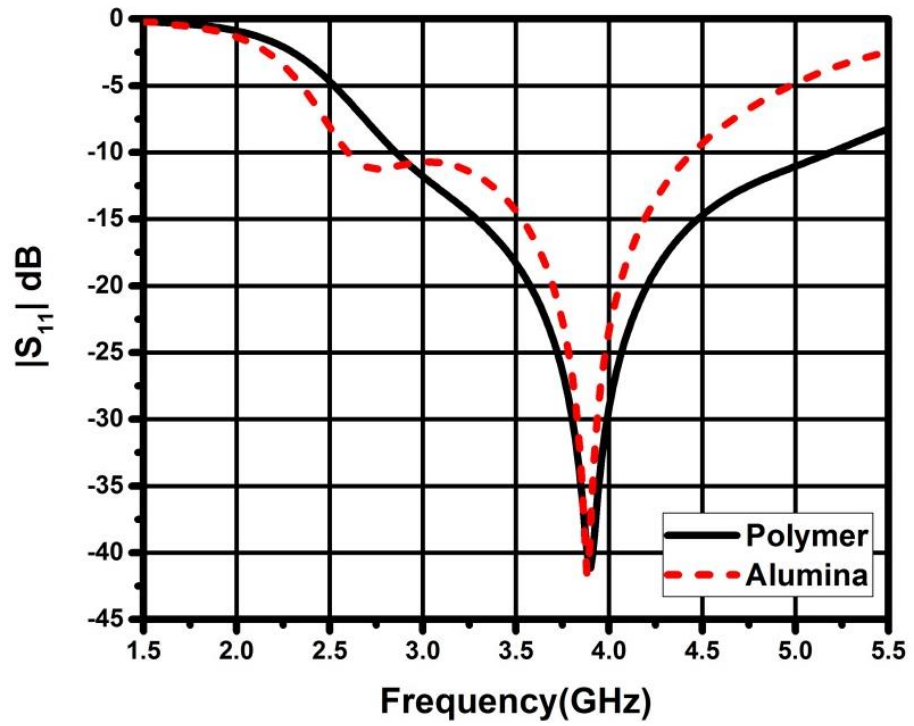

Fig. 11 Comparison of reflection coefficient versus frequency for the polymer based DRA and alumina based DRA

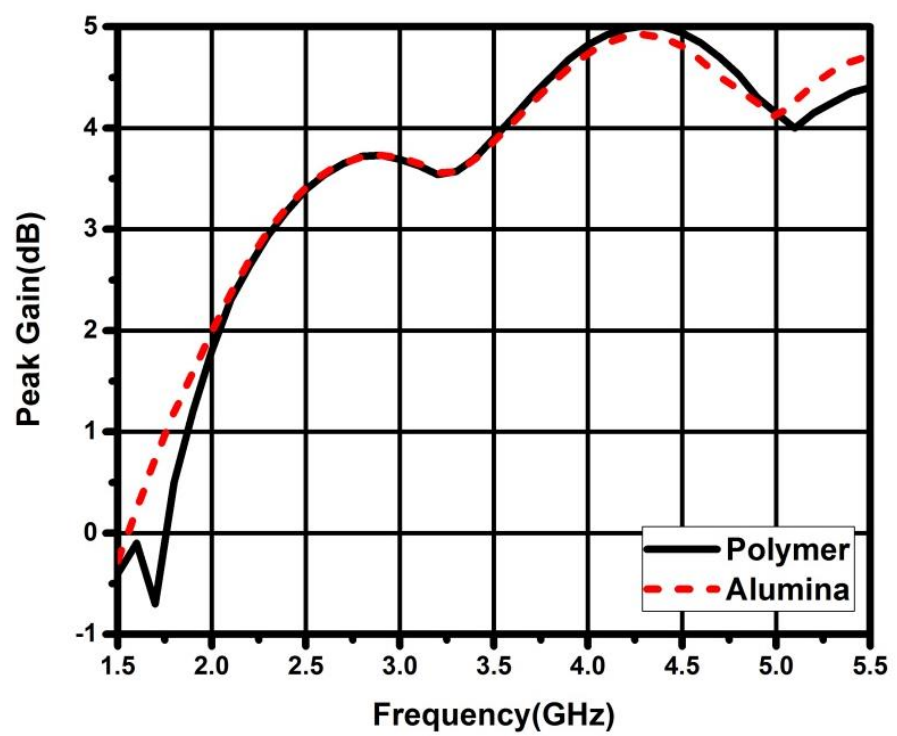

Fig. 12 Comparison of peak gain versus frequency for the polymer based DRA and alumina based DRA

TABLE III: COMPARATIVE PARAMETERS FOR POLYMER AND ALUMINA BASED DRA

\begin{tabular}{ccc}
\hline Parameter & Polymer based DRA & Alumina (ceramic) based DRA \\
\hline Resonant Frequency & $3.8 \mathrm{GHz}$ & $3.8 \mathrm{GHz}$ \\
Bandwidth & $63.2 \%$ & $61.3 \%$ \\
Mass & $12.67 \mathrm{~g}$ & $14.43 \mathrm{~g}$ \\
Density & $2070 \mathrm{Kg} / \mathrm{m}^{3}$ & $2770 \mathrm{Kg} / \mathrm{m}^{3}$ \\
Volume & $6119.37 \times 10^{-9} \mathrm{~m}^{3}$ & $5209 \times 10^{-9} \mathrm{~m}^{3}$ \\
Thermal Conductivity & $0.70 \mathrm{~W} / \mathrm{m} / \mathrm{K}$ & $0.76 \mathrm{~W} / \mathrm{m} / \mathrm{K}$ \\
Dielectric Constant & 3.45 & 9.8 \\
Resonance Dip & $-41.5 \mathrm{~dB}$ & $-41.1 \mathrm{~dB}$ \\
Peak Gain & $4.5 \mathrm{~dB}$ & $4.42 \mathrm{~dB}$ \\
Fabrication & Easy & Complex \\
Cost & Inexpensive & Costly \\
\hline
\end{tabular}




\section{EXPERIMENTAL RESULTS}

The structure of proposed DRA is fabricated by additive manufacturing i.e. 3D printing (3DP). It is a layer-by-layer approach of fabricating 3D objects. Commercially available SMA connector is used to provide coaxial feed. Fig. 13 exhibits the fabricated DRA.

The reflection coefficient is measured using ROHDE \& SCHWARZ, FSH8 handheld network analyzer, while the radiation characteristics are measured using a basic antenna measurement setup. The comparison between simulated and measured variations of reflection coefficient versus frequency for proposed DRA is shown in Fig. 14. The simulated results shows that the proposed DRA resonates at $3.8 \mathrm{GHz}$, offering an impedance bandwidth of $63.2 \%$, while the measured result shows that DRA resonates at $\sim 3.7 \mathrm{GHz}$, offering $64 \%$ impedance bandwidth for $\left|\mathrm{S}_{11}\right|<-10 \mathrm{~dB}$. Thus, simulated and measured results are showing very good agreement across the operating band. The small difference in the results is mainly due to the fabrication inconsistencies like air gaps between the DRA and the ground plane, imperfections while drilling the hole for probe insertion, etc.

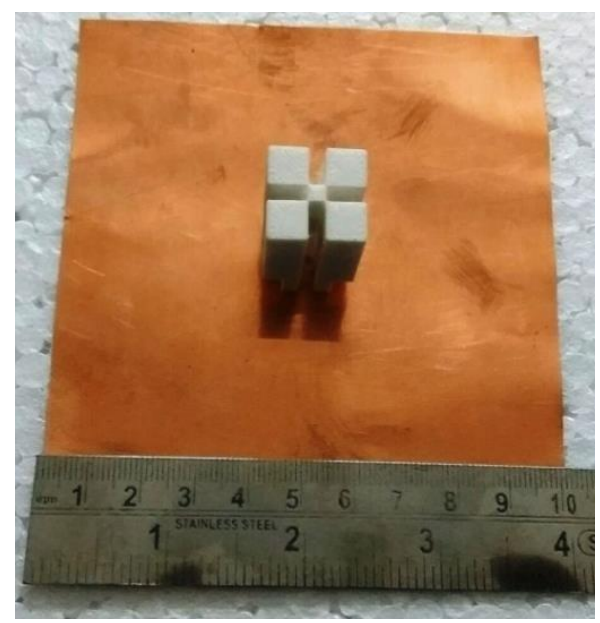

Fig. 13 Fabricated model of proposed DRA

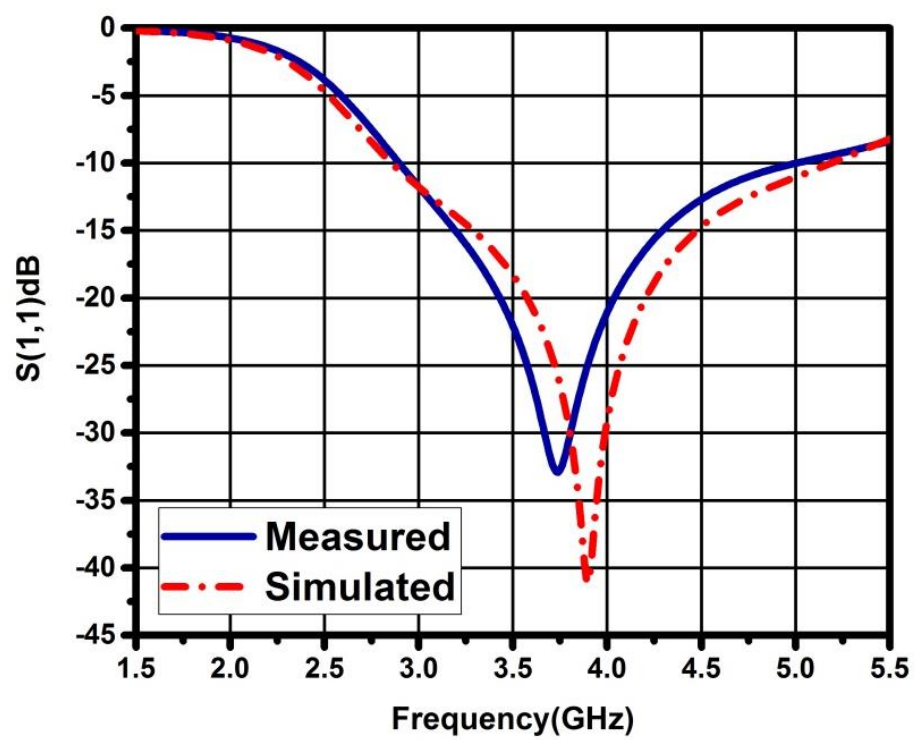

Fig. 14 Comparison of simulated and measured reflection coefficient for the proposed DRA 
Antenna has been fed to radiate by the mean of coaxial cable. Fig. 15 shows the measured and simulated co-polar as well as cross-polar radiation patterns in E-plane (phi=0) and $\mathrm{H}=$ plane (phi=90) at frequencies 3.3, 3.8 and 4.4 GHz. It is clearly observed that cross-polar level is very lower than copolar level which verifies the linear polarization of antenna. The null in the boardside direction is clearly visible for all radiation patterns, which verifies the presence of TM mode.
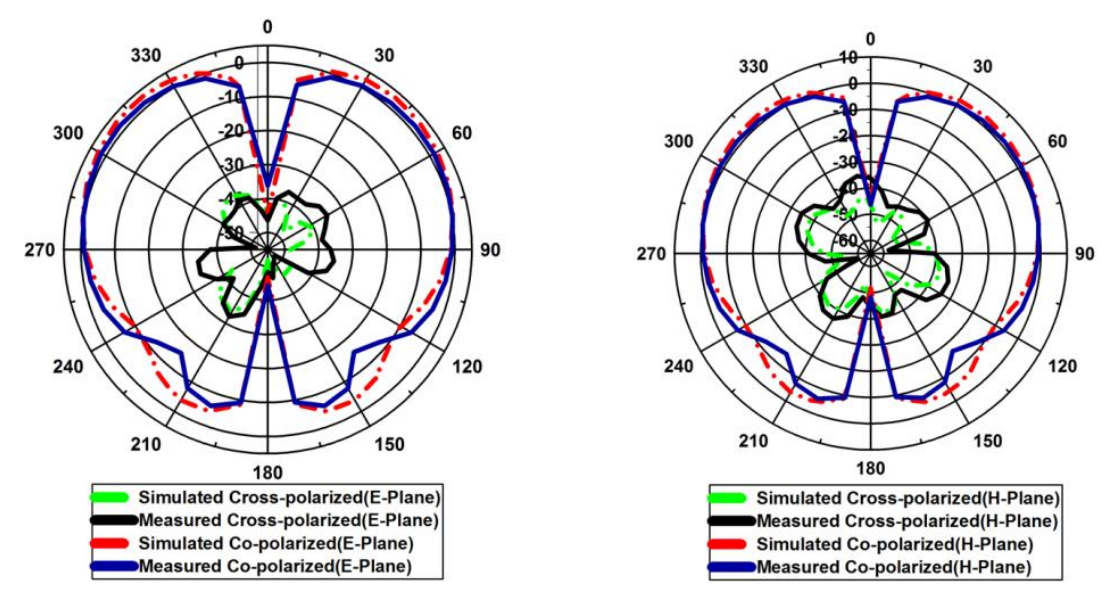

(a)
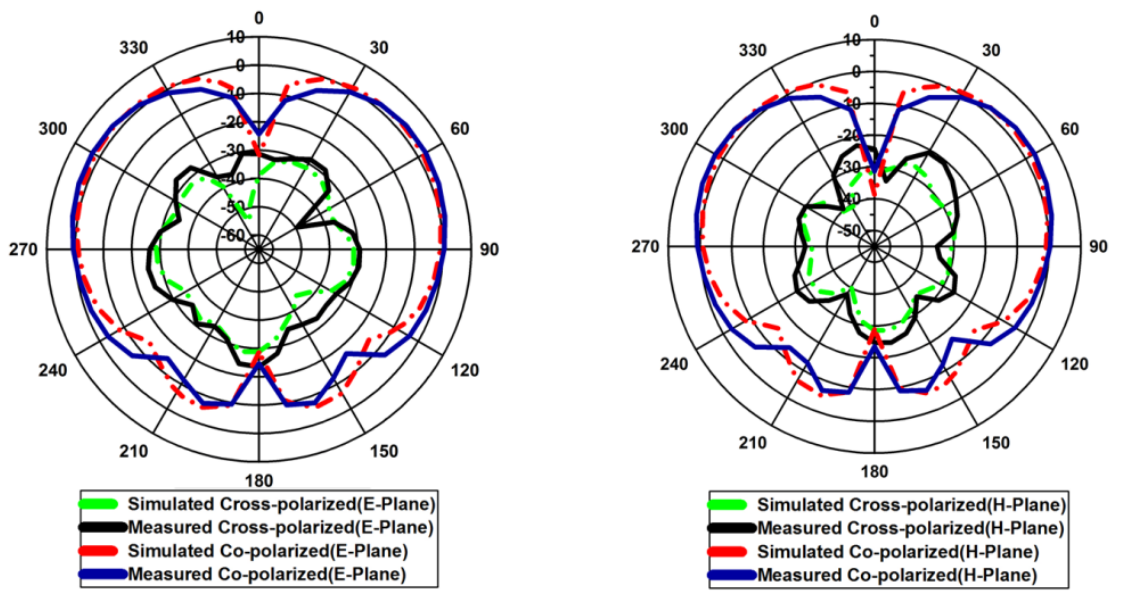

(b)
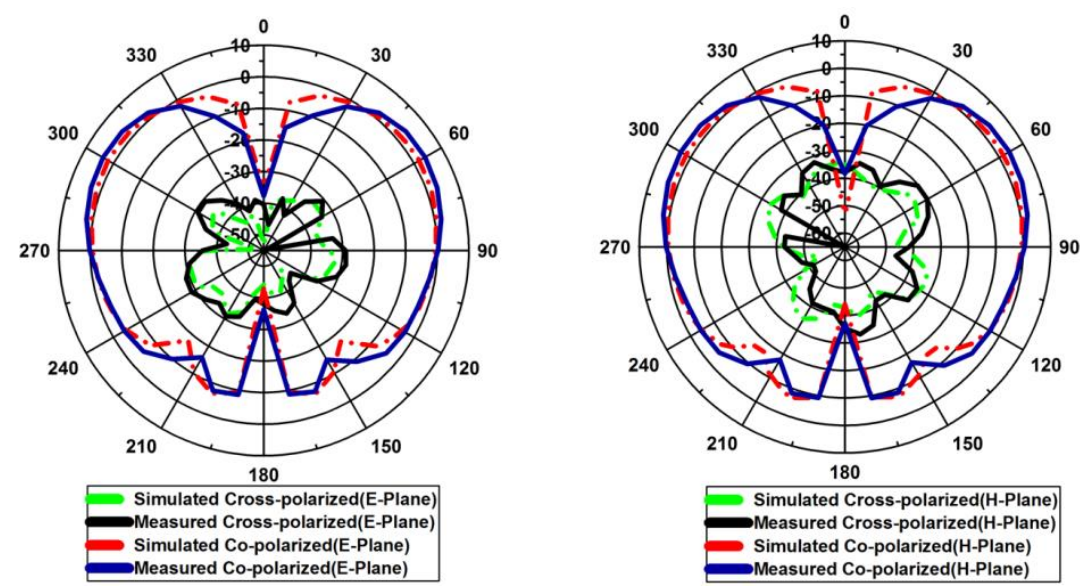

(c)

Fig. 15 Comparison of measured and simulated radiation patterns (E-Plane and H-Plane) of the proposed DRA: (a) 3.3 GHz, (b) $3.8 \mathrm{GHz}$, (c) $4.4 \mathrm{GHz}$ 
The proposed antenna radiates conical beam pattern. In order to evaluate the uniformity received the signal of all subscribers around the antenna, the radiation patterns in XY plane at the beam direction with different theta angle $\left(0^{\circ}, 30^{\circ}, 50^{\circ}, 70^{\circ}\right)$ is shown in Fig. 16. The main beam direction of the pattern is found at angle $\sim 50^{\circ}$. It is nearly omni-directional pattern with reference to polar plot for all three selected frequency i.e. $3.3 \mathrm{GHz}, 3.8 \mathrm{GHz}$ and $4.4 \mathrm{GHz}$.

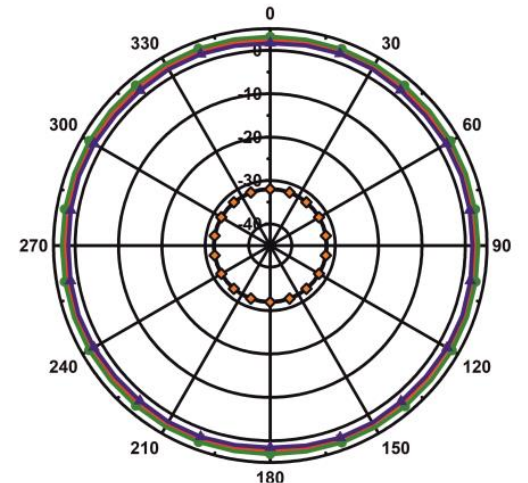

(a)

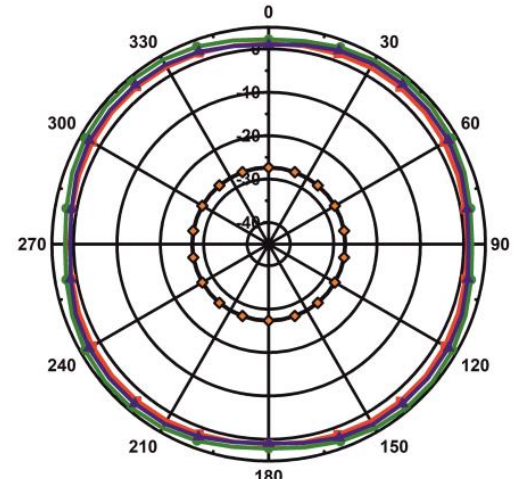

(b)

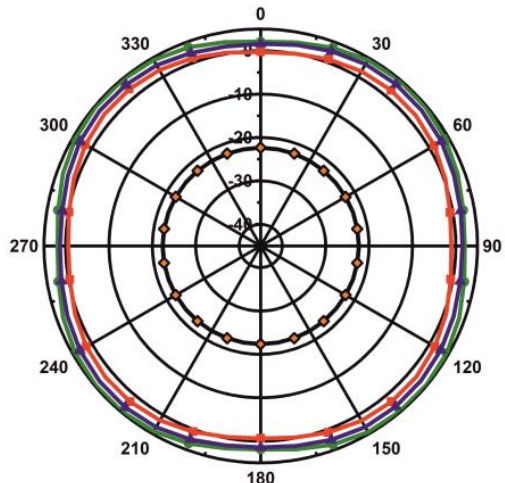

(c)

$\leadsto \theta=0^{0}$

$-\theta=30^{\circ}$

$\rightarrow \theta=50^{\circ}$

$-\theta=70^{\circ}$

Fig. 16 Simulated radiation patterns (XY-Plane) of the proposed DRA: (a) $3.3 \mathrm{GHz}$, (b) $3.8 \mathrm{GHz}$, (c) $4.4 \mathrm{GHz}$

The comparison plot of measured and simulated variation of peak gain versus frequency is shown in Fig. 17. The measured peak gain at $3.8 \mathrm{GHz}$ is $4.6 \mathrm{~dB}$ while simulated peak gain at $3.8 \mathrm{GHz}$ is $4.5 \mathrm{~dB}$. It is also noticed that the gain is almost stable for the complete bandwidth of operation. Thus, the proposed DRA offers lower losses and are comparable to the other regular geometries in the DRA family. Table IV shows the judgment of the proposed DRA with the superlative cases of existing inspects. It can be observed that the proposed antenna not only achieves wider bandwidth, but also compact volume.

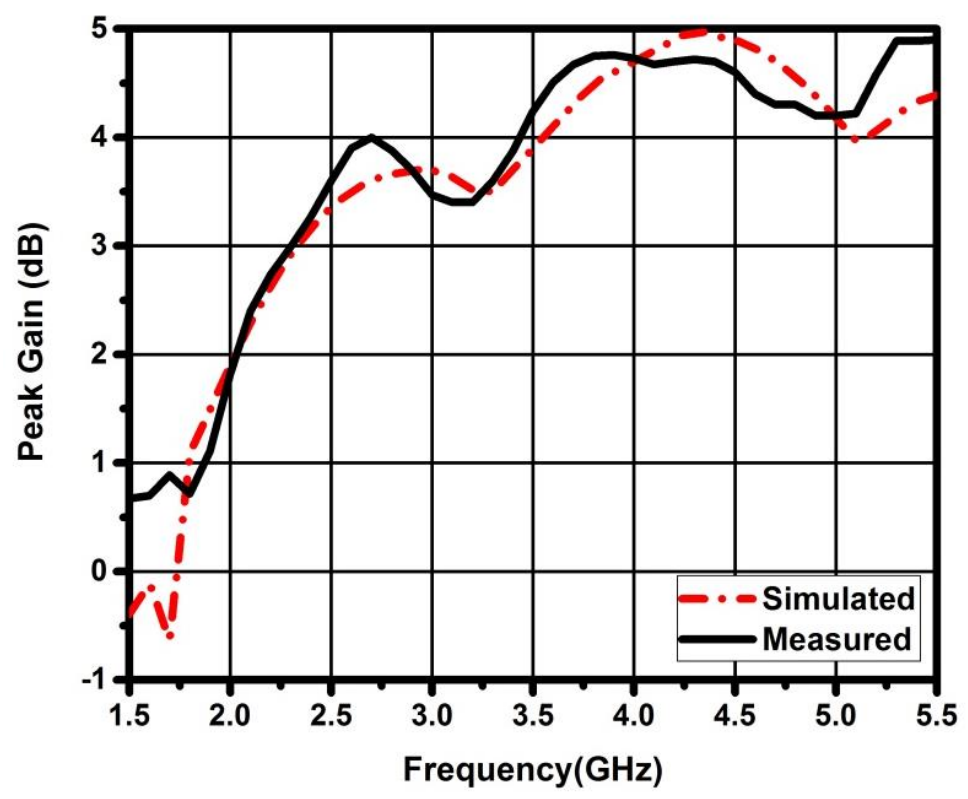

Fig. 17 Measured gain as a function of frequency for proposed DRA 
Journal of Microwaves, Optoelectronics and Electromagnetic Applications, Vol.16, No. 3, September 2017879 DOI: http://dx.doi.org/10.1590/2179-10742017v16i31019

TABLE IV: COMPARISON OF THE PROPOSED STRUCTURE

\begin{tabular}{cccccc}
\hline Shape & $\boldsymbol{\varepsilon}_{\boldsymbol{r}}$ & $\mathbf{V}\left(\mathbf{1 0}^{-\mathbf{6}} \mathbf{m}^{\mathbf{3}}\right)$ & $\mathbf{B W}(\boldsymbol{\%})$ & $\mathbf{f}_{\mathbf{r}}(\mathbf{G H z})$ & $\mathbf{R e f}$ \\
\hline Rectangular & 9.8 & 13.5 & 56 & 3.2 & 19 \\
Rectangular & 10 & 6.54 & 32.6 & 4.6 & 20 \\
Rectangular & 9.8 & 9.39 & 33 & 3.9 & 21 \\
Cylindrical & 10 & 9.12 & 19.1 & 3.8 & 22 \\
Tetraskelion & 9.8 & 6.48 & 57.5 & 5.25 & 23 \\
Quadruple-shaped & $\mathbf{3 . 4 5}$ & $\mathbf{6 . 1 2}$ & $\mathbf{6 3 . 2}$ & $\mathbf{3 . 8}$ & PS
\end{tabular}

$\varepsilon_{r}$ - Dielectric constant, $V$ - Volume, $B W-$ Bandwidth, $f_{r}-$ Resonant frequency, $P S$ - Proposed Structure

\section{CONCLUSION}

A novel class of rectangular DRA along with Quadruple-shaped based geometry for biodegradable polymer based material has been successfully implemented. This antenna has a simple-interesting structure and relatively compact volume of $6.08 \mathrm{~cm}^{3}$. The DRA resonates at $3.8 \mathrm{GHz}$, offering an impedance bandwidth of $63.2 \%$ for $\left|\mathrm{S}_{11}\right|<-10 \mathrm{~dB}$ from 2.8 to $5.2 \mathrm{GHz}$. Proposed DRA has many more advantages over the conventional DRA such as low cost, easy fabrication, light weight and a wider bandwidth. This makes the DRA suitable for practical use in the wireless communication systems. Practical applications are like WLAN (5.15-5.35 GHz) and Wi-Max (3.4-3.69 GHz) system. The peak gain of the DRA is $4.6 \mathrm{~dB}$ at the resonant frequency with high radiation efficiency. To the best of our knowledge, such geometry has not been explored so far for a DRA. Thus, the varieties of eco-designed DRA are possible by the adoption of polymer dielectric resonators with very effective cost.

\section{ACKNOWLEDGMENT}

The authors would like to acknowledge Prof. Navneet Gupta, Head of the Department, Electrical \& Electronics Engineering, Birla Institute of Technology and Science, Pilani, Rajasthan, India and Shailendra Singh, Deputy Engineer, Bharat Electronics Limited, India, for their support.

\section{REFERENCES}

[1] A. Petosa, "Dielectric resonator antenna handbook. Norwood, MA", USA: Artech House, 2007.

[2] J. Kumar and N. Gupta, "Performance analysis of dielectric resonator antennas", Wireless Personal Communications, vol. 75, no 2, pp. 1029-1049, Mar. 2014.

[3] M. Lapierre, Y. M. M. Antar, A. Ittipiboon, and A. Petosa, "Ultra wideband monopole/dielectric resonator antenna", IEEE Microwave and Wireless Components Letters, vol. 15, no. 1, pp. 7-9, Jan. 2005.

[4] J. Kumar and N. Gupta, "Bandwidth and gain enhancement technique for Gammadion cross dielectric resonator antenna" Wireless Personal Communications, vol. 85, no. 4, pp. 2309-2317, 2015.

[5] G. Drossos, Z. Wu, and L. E. Davis, "The air gap effect on a microstrip-coupled cylindrical dielectric resonator antenna", Microwave and Optical Technology Letters, vol. 20, no. 1, pp. 36-40, Jan. 1999.

[6] J. Kumar and N. Gupta, "Linearly Polarized Asymmetric Dielectric Resonator Antennas for 5.2 GHz WLAN Applications”, Journal of Electromagnetic Waves and Applications, vol. 29, no. 9, pp. 1228-1237, 2015. 
Journal of Microwaves, Optoelectronics and Electromagnetic Applications, Vol.16, No. 3, September 2017880 DOI: http://dx.doi.org/10.1590/2179-10742017v16i31019

[7] H. Nawaz, and M. Ali Babar Abbasi. "Wide-band dielectric resonator antenna using K-shaped fractal", Microwave and Optical Technology Letters, vol. 58, no.6, pp. 1504-1507, 2016.

[8] A. A. Kishk, X. Zhang, A. W. Glisson, and D. Kajfez, "Numerical analysis of stacked dielectric resonator antennas excited by a coaxial probe for wideband applications", IEEE Transactions on Antennas and Propagation, vol. 51, no. 8, pp. 1996-2006, Aug. 2003.

[9] A. Petosa, N. Simons, R. Siushansian, A. Ittipiboon, and M. Cuhaci, "Design and analysis of multisegment dielectric resonator antennas", IEEE Transactions on Antennas and Propagation, vol. 48, no. 5, pp. 738-742, May 2000.

[10] A. A. Kishk, Y. Yin, and A. W. Glisson, “Conical dielectric resonator antennas for wide-band applications”, IEEE Transactions on Antennas and Propagation, vol. 50, no. 4, pp. 469-474, Apr. 2002.

[11] A. A. Kishk, "Wide-band truncated tetrahedron dielectric resonator antenna excited by a coaxial probe", IEEE Transactions on Antennas and Propagation, vol.51, no. 10, pp. 2913-2917, Oct. 2003.

[12] A. G. Walsh, C. S. De Young, and S. A. Long, "An investigation of stacked and embedded cylindrical dielectric resonator antennas", IEEE Antennas and Wireless Propagation Letters, vol. 5, pp. 130-133, Jan. 2006.

[13] C. S. De Young and S.A. Long, "Wideband cylindrical and rectangular dielectric resonator antennas", IEEE Antennas and Wireless Propagation Letters, vol. 5, pp. 426-429, Oct. 2006.

[14] M. Simeoni, R. Cicchetti, A. Yarovoy, and D. Caratelli, "Supershaped dielectric resonator antennas", IEEE International Symposium on Antennas and Propagation Society (APSURSI'09), Charleston, SC, pp. 1-4, Jun. 2009.

[15] Ansys, H. F. S. S. "ver. 15.0, ANSYS" Inc., Southpointe 275.

[16] CST Microwave Studio. Computer Simulation Technology, Framingham, MA, USA, 2015.

[17] S. Fakhte, H. Oraizi, and R. Karimian, "A novel low cost circularly polarized rotated stacked rectangular dielectric resonator antenna”, IEEE Antennas and Wireless Propagation Letters, vol. 13, pp. 722-725, 2014.

[18] L. Zou, "Dielectric resonator antennas from multifunction microwave devices to optical nano-antennas", Ph.D. Thesis, School of Electrical and Electronic Engineering, University of Adelaid, Australia, March 2013.

[19] J. Kumar and N. Gupta, "Investigation on Rudimentary Geometries of Dielectric Resonator Antenna", The 36 Progress In Electromagnetics Research Symposium Proceedings (PIERS 2015), Prague, Czech Republic, pp. 21492152, July 2015.

[20] Y. F. Wang, T. A. Denidni, Q. S. Zeng, and G. Wei, "Band-notched UWB rectangular dielectric resonator antenna", Electronics Letters, vol.50, no.7, pp.483,484, March 27, 2014.

[21] J. Kumar, and N. Gupta, "Investigation on microwave dielectric materials for dielectric resonator antennas", International Journal of Applied Electromagnetics and Mechanics, vol. 47, no. 1, pp. 263-272, 2015.

[22] L. F. Zou, D. Abbott, and C. Fumeaux, "Omnidirectional cylindrical dielectric resonator antenna with dual polarization”, IEEE Antennas and Wireless Propagation Letters, vol. 11, pp. 515-518, 2012.

[23] J. Kumar, B. Mukherjee, and N. Gupta, "A Novel Tetraskelion Dielectric Resonator Antenna for Wideband Applications," Microwave and Optical Technology Letters, vol. 57, no. 12, pp. 2781-2786, 2015. 